\title{
A METHOD FOR DETERMINING THE VOLUME CHANGES OCCURRING IN METALS DURING CASTING
}

\author{
By C. M. Saeger, jr., and E. J. Ash ${ }^{1}$
}

\section{ABSTRACT}

This paper reviews methods which have been proposed and used for determining the various types of shrinkage undergone by a cooling metal. The three types of shrinkage to be considered may be defined as (a) shrinkage in the liquid metal, (b) shrinkage during solidification, and (c) shrinkage in the solid state. It also considers briefly the sand-cast cone method for determining total shrinkage during casting and the more fundamental procedure of constructing a specific volume-temperature curve for each metal or alloy from some temperature well above the melting point or melting range to room temperature. The specific volume-temperature curve in the range of liquid metal is constructed from data secured by application of the crucible-immersion method; that is, by filling a crucible of known volume with liquid metal at known temperature. Since the mass of the sample of liquid metal is the same as that of the sample at room temperature, the specific volume of the liquid can be readily calculated. Data on the contraction of the solid metal were obtained by direct observations of the change in length with change in temperature of a sand-cast bar of metal. The difference between the specific volume of the solid metal and of the liquid metal at the melting point is the shrinkage during solidification. In the case of an alloy, shrinkage during solidification occurs over a range of temperature.

\section{CONTENTS}

I. Introduction

1. Importance of problem

2. Definitions and general aspects of shrinkage...

II. Previous methods

1. Dilatometric $\ldots \ldots \ldots$

2. Buoyancy

3. Pyknometer........... 41

4. Sand-cast sphere, cone or cylinder 41

III. Methods and apparatus. 42

1. Sand-cast cone. 42

2. Determination of the specific volume-temperature curve..- 42

(a) Liquid metal 43

(b) Solid metal

(c) Solidification range 47

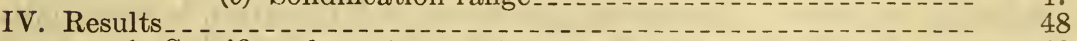

1. Specific volume-temperature curves 48

V. Discussion

VI. Summary

VII. Acknowledgments

VIII. Bibliography

\section{INTRODUCTION}

\section{IMPORTANCE OF PROBLEM}

In 1928 the American Foundrymen's Association, through its Committee on Gray Iron Castings, proposed to the Bureau of Standards the desirability of an investigation on the "liquid shrinkage" of

1 Resea ch Associate representing American Foundrymen's Association. 
metals. A research associate was appointed in April, 1929, to work on the investigation.

It was soon evident, however, that the information desired by the practical foundryman involves much more than could properly be included under the term "liquid shrinkage." The foundryman, in producing a satisfactory casting, has a threefold interest in the shrinkage problem-first, he must make the dimensions of his pattern greater than the dimensions of the desired casting; second, he must employ all means possible to attain the maximum density in the casting and to produce a metal free from porosity, piping, and gas holes; third, he must consider the design of his casting in its relation to the propensity of the casting to crack in the mold as a result of stresses set up by differential shrinkage particularly at sharp angles or abrupt changes in cross section.

\section{DEFINITIONS AND GENERAL ASPECTS OF SHRINKAGE}

When a molten metal or alloy is cooled to ordinary temperature, a change of volume takes place. This change is the summation of three consecutive volume changes which for the purpose of the present paper, are defined as follows:

1. Shrinkage or contraction of liquid metal is the change in volume on cooling from any temperature in the liquid state to some lower temperature in liquid state.

2. Shrinkage or contraction during solidification is the volume change of a pure metal in passing from the liquid state to the solid state at the freezing point, or the change in volume of an alloy in passing from the liquid state at the beginning of the freezing range to the solid state at the end of the freezing range. The shrinkage undergone during solidification of a eutectic or of an inter-metallic compound, freezing at a constant temperature, is similar to that of a pure metal.

3. Shrinkage or contraction of solid metal is the change in volume on cooling from some temperature below its freezing point or range to a lower temperature.

The shrinkage during solidification of an alloy with a freezing range will include, therefore, all three types of shrinkage defined above; that is, liquid, solidification, and solid.

Shrinkage or contraction of the liquid is a definite physical property of a metal or alloy. This value, therefore, is fixed and constant for each metal or alloy. The shrinkage during solidification is essentially a constant for a pure metal, eutectic, or intermetallic compound. However, in alloys of the solid-solution type, the solid metal, which separates from the melt during freezing continually changes in composition and the shrinkage during solidification is correspondingly complicated. During this selective crystallization stresses may be set up on account of the different coefficients of expansion of metal of different composition. According to Davey $(1)^{2}$ all crystals are produced in a state of strain.

The volume change of a metal or alloy in the solid state may also be variable. Stresses may exist in a cast alloy of the solid-solution type as the result of progressive solidification and structural trans-

2 The figures given in parentheses here and throughout the text relate to the reference numbers in the bibliography given at the end of this paper. 
formations after solidification. Such stresses may also be due partly to the temperature gradients set up during cooling.

As a result of these stresses in a cast alloy, the observed contraction of a bar, designated as patternmaker's shrinkage, may differ from that which would be calculated from the true thermal expansion of the alloy. In deternining the thermal expansion of an alloy, the specimen is heated or cooled as nearly uniformly as possible. The alloy attains equilibrium in temperature and tends to approach equilibrium in composition.

Another factor which influences the difference between the true thermal expansion of a metal or alloy and the pattern-maker's shrinkage is the apparent failure of a casting to register the true shrinkage taking place at and slightly below the freezing point or range. The cause of this may possibly be due to the fact that material at the grain boundaries does not possess sufficient rigidity to register the actual contraction of the grains or crystallites. This situation makes it impracticable to determine the shrinkage or contraction of a solid alloy casting by using thermal expansion measurements.

It is of interest to know the relative tendency of some metals and alloys to distribute their shrinkage between an external pipe and internal voids. Except where conditions are such that a complete rigid shell is formed about a cooling mass of molten metal before the interior has reached the freezing temperature, the shrinkage caused by contraction of the liquid interior will result in a depression in the upper surface (external pipe). Shrinkage that takes place during the change of state may contribute largely to the production of internal voids when such tendency is exhibited by the metal or alloy. This characteristic to form internal voids is not so pronounced in pure metals as it is in some alloys.

The distribution of the shrinkage or contraction during solidification, whether in the form of an external pipe, internal pipe, or small cavities (porosity) throughout the casting, will depend largely on the following factors: (a) The amount of shrinkage during solidification; (b) the freezing temperature of the metal; $(c)$ type of metal, whether it is pure, eutectic, intermetallic compound, solid solution, or any combination of these; $(d)$ fluidity of the metal; $(e)$ heat conductivity, heat capacity, and pouring temperature of the metal; $(f)$ location and design of gates and risers; $(g)$ ratio of surface area to volume; and $(h)$ heat capacity, heat conductivity, and initial temperature of the mold material.

The first five factors may be grouped as properties of the metal, while the remaining factors may be classed as foundry or casting practice or technique. It is obvious, from the number and complexities of the factors influencing the amount and distribution of the shrinkage in the casting of any particular metal or alloy that it is very difficult, if indeed possible, to determine the influence of all these various factors by means of any single experimental procedure.

\section{PREVIOUS METHODS}

Methods that have been previously employed for measuring the volume changes undergone by a metal in cooling from the liquid state to room temperature will be reviewed under four headings-dilatometric; buoyancy; pyknometer; sand-cast sphere, cone, or cylinder. 


\section{DILATOMETRIC}

Dilatometric methods consist in observing the change in volume of a given material with change in temperature. In the solid state the specimen is usually in the form of a bar, and the change in volume is calculated from changes in linear dimension measured directly. For observing the change in volume with change in temperature in the liquid state, the molten metal is heated or cooled in a container of known volume calibrated to give directly the corresponding volume change. Such methods were employed by most of the early workers for determining the specific volume of metals in the liquid state. The work of Matuyama is typical (2).

A differential dilatometer was used by Goodrich (3) on a number of low-melting metals and alloys. The metal sample was placed in one of two similar bulbs and the difference in pressures in the bulbs with change in temperature was observed. This method is limited to low-melting-point metals and alloys on account of the lack of suitable materials for containers. The method is also limited by the extreme precautions necessary in guarding against the formation of internal cavities, which appreciably influence the validity of the results.

Benedicks, Berlin, and Phragmen (4) determined the density of molten tin, lead, and low-carbon iron by means of a double manometer, a column of mercury being used as the comparison liquid. Great ingenuity was shown in the construction of $U$ tubes of refractory material capable of retaining the metal and, at the same time, supporting the requisite pressure of nitrogen or other inert gas. This work has recently been continued and extended by Benedicks and coworkers (5) on iron, nickel, and iron alloys in the molten state.

An approximate determination of the "solid" contraction of a cast metal may be made by the method developed by Keep (6), which consisted in measuring the change in length of a cast bar as it cooled from the freezing temperature to room temperature. This method has been extensively used by Turner and his associates ( 7 , $8,9,10,11)$, Chamberlain (12), Wüst (13), and also by Johnson and Jones (14).

A simplified method used by Anderson (15) for determining patternmaker's shrinkage consisted in casting a bar in a mold of known length and measuring the length of the resulting bar.

\section{BUOYANCY}

Buoyancy methods consist in measuring at various temperatures the buoyant effect of an inactive liquid of known density and thermal expansion upon a definite mass of the inetal, either liquid or solid, under examination. For lower temperatures an oil is used, while molten sodium chloride or similar salts are used for the higher temperatures.

This method was used by Bornemann and Sauerwald (16), Endo (17, 18), Honda and Endo (19), Russell, Allen, and Goodrich (20), Matuyama $(21,22)$, and Honda, Kase, and Matuyama (23).

Goodrich (3) has pointed out that the results from this method are subject to several inaccuracies. When investigating low-meltingpoint alloys and metals, the immersion bath is usually an oil, the density of which changes not only with temperature, but also with time at higher temperature. Correct temperature of the specimen can not readily be obtained at the time of making the determination. 
Since the volume changes were always determined during changes of temperature, the temperature of the metal would always lag behind that indicated by the thermometer. Temperature gradients may exist in the heating or cooling bath itself, since stirring is not permissible as this would interfere with the determination of the buoyancy. In a recent article, Matuyama (22) has attempted to meet these criticisms of the method.

In the buoyancy method, as in the dilatometer method, gas bubbles or shrinkage cavities which may form inside the specimen during: freezing, would seriously affect the results of a determination of the change in volume during solidification.

Desch and Smith (24) have attempted to determine the density of molten steel by observing the weight of a sinker attached to one arm of a balance in air, in mercury, and in the liquid steel. It is difficult to obtain a suitable sinker that is not attacked by the liquid steel and the mechanical difficulties during the progress of a determination are great indeed.

\section{PYKNOMETER}

Edwards and collaborators $(25,26,27)$ have measured the specific volume of molten aluminum and copper-aluminum alloys by means of a pyknometer, which the authors called a "densimeter." A crucible of known volume was filled with molten metal at a definite temperature and the metal allowed to freeze.

The weight of the resulting ingots and the volumes of the crucibles at the respective sampling temperatures gave information from which the specific volume-temperature curve in the liquid metal was constructed. The method is sufficiently accurate, but like most methods it is applicable only over a limited temperature range.

\section{SAND-CAST SPHERE, CONE, OR CYLINDER}

Attempts have been made to measure the total shrinkage undergone by cast iron in the liquid state and during solidification by comparing the weight and volume of an "unfed" cast specimen with the weight and volume of a similarly cast but "sound" specimen. The weight of the sound or reference specimen was obtained from a "fed" casting or from the calculated weight of the specimen as determined from the volume and the maximum density of the metal (usually that at the gate). From the difference in weight between the unfed casting and the sound or reference specimen the combined volume change due to the shrinkage of the metal in the liquid state and also the shrinkage taking place during solidification may be determined.

West (28) has reported results on cast iron obtained in this manner. Two spheres of the same dimensions were cast, one being fed from a heavy riser and the other being unfed. The experiments were repeated on spheres of larger sizes. His results were not consistent, however. Smalley (29) conducted similar experiments on conically shaped specimens of gray cast iron, to determine the relation between shrinkage during solidification and the tendency to form a pipe.

Longden (30) has reported results on cylinders and spheres, fed and unfed, and Schwartz (31) cast four spheres from the same runner and calculated the shrinkage from the density of the metal in the gate and the weight and volume of the spheres. 
These methods are similar in principle and undoubtedly gave useful results to the foundry in which they were used. However, there is no means of differentiating between the shrinkage of the liquid metal and that occuring during solidification. Furthermore, since feeding occurs during the entire pouring period, it is difficult to determine just what was measured by the foregoing methods.

\section{METHODS AND APPARATUS}

Two methods were investigated as a means for determining the volume changes occurring when a molten metal is cooled down to ordinary temperature. Attempts were first made to obtain the data from sand-cast cones. It was soon apparent that true values for the shrinkage were not obtainable by this method. Consequently attention was focused upon the investigation of methods for obtaining data from which specific volume-temperature curves could be constructed covering the range from the molten state to room temperature. It was believed that the best evaluation of the different factors constituting the over-all shrinkage from molten metal to solid at room temperature could be obtained from a curve of this type.

\section{SAND-CAST CONE}

A conical casting, designed to be cast base up, in sand, was first used in an effort to determine the volume changes due to shrinkage in the liquid metal and during solidification. After casting 24 specimens it was obvious that true shrinkage values were not obtained by this method, presumably for the following reasons:

1. The temperature of the metal at the instant the mold cavity is completely filled can not be determined because there is no uniformity of temperature throughout the mass of liquid metal.

2. A volume change takes place in some of the metal during the pouring period as molten metal in contact with the sand surface will receive more or less chill and a solid shell of metal will be formed while the specimen is being poured, thus diminishing the true shrinkage of the casting.

Therefore, no further consideration of this method was given in this investigaton. However, it is realized that a method of this type may be quite useful and satisfactory in further phases of an investigation of this nature when attention is turned to the influence of foundry variables upon the distribution of the types of shrinkage. Further details of this method have been presented in a preliminary report on the investigation (32).

\section{DETERMINATION OF THE SPECIFIC VOLUME-TEMPERATURE CURVE}

It has already been pointed out that when molten metal is cooled down to the solid state at room temperature, the resulting change in volume is the summation of three successive volume changes, namely, shrinkage of the liquid metal, shrinkage during solidification, and shrinkage of the solidified metal.

In the curve (fig. 1), $V_{a}-V_{b}$ represents the change in specific volume with change in temperature of a metal in the liquid state as it cools from some temperature $a$ to the freezing temperature $b$. The interval $V_{b}-V_{c}$ represents the change in specific volume of a metal in 
passing from the liquid state at temperature $b$ to the solid state at temperature $c$. The interval $V_{c}-V_{d}$ represents the change in specific volume of the solid metal as it cools from the freezing point $c$ to room temperature $d$.

The change in volume in per cent for each interval can be calculated from the difference in specific volume for that particular interval, thus $\frac{V_{a}-V_{b}}{V_{a}} \times 100$ is the per cent change in volume due to the metal cooling from temperature $a$ to temperature $b$ in which $V_{a}$ and $V_{b}$ represent the specific volumes at these two temperatures. Likewise, the change

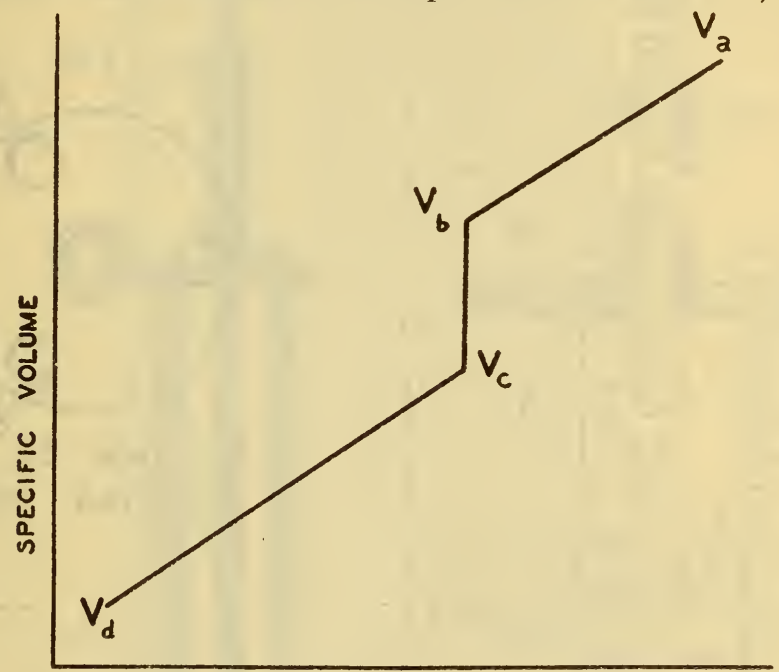

TEMPERATURE

Frgure 1.-Typical specific volume-temperature curve of a metal

in volume, in per cent, due to the shrinkage during solidification is equal to $\frac{V_{b}-V_{c}}{V_{b}} \times 100$, and that due to the shrinkage of the solid metal is equal to $\frac{V_{c}^{b}-V_{d}}{V_{c}} \times 100$.

(a) LIQUID METAL

Previous investigators (25) have been able to determine the specific volume temperature relations of molten metals by means of what was essentially the pyknometer method. As pointed out before, the results heretofore reported were limited to the lower melting point metals and alloys. In the present work it was desired to obtain experimental data on cast irons. Hence it was necessary to devise an apparatus which was of such form that it could be built of materials that could be used over a wider range of temperatures than previously used apparatus.

The apparatus as finally used is shown in Figures 2 and 3 . It is essentially a pyknometer, but is designated as a "crucible immersion apparatus." The crucible, lid, and supporting rods were made of Acheson graphite.

By means of this apparatus it was possible to isolate a known volume of liquid metal at a definite and predetermined temperature 
from a ladle of molten metal. The procedure used was as follows: The crucible was filled by immersing it in a ladle of molten metal and sufficient time was allowed for the crucible to come to the temperature of the surrounding metal or to allow both crucible and metal to cool down to the temperature at which it was desired to obtain a sample. When the desired temperature was reached, the lid was pressed down firmly on the crucible, and the whole assembly removed from the ladle of metal.

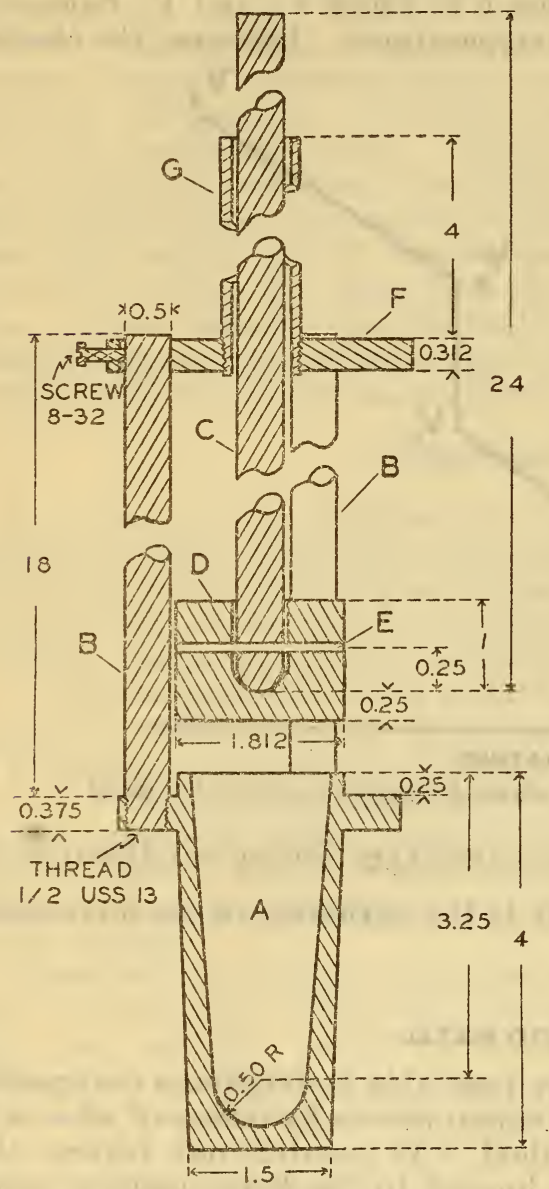

\section{DIMENSIONS IN INCHES}

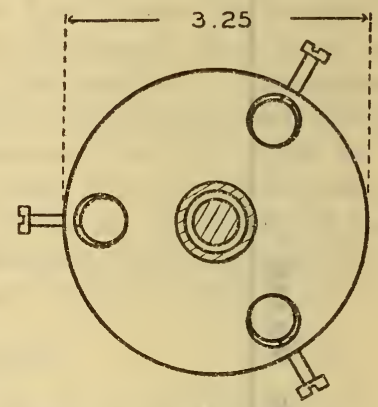

TOP VIEW OF

HOLDING DEVICE

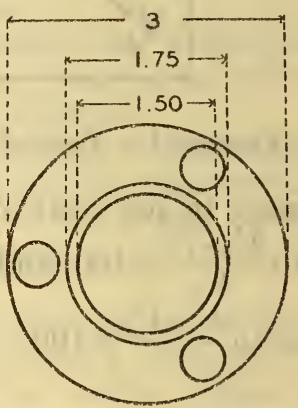

TOP VIEW OF CRUCIBLE

\section{LONGITUDINAL SECTION}

OF ASSEMBLY

FIGURE 2.-Crucible immersion apparatus

$A$, crucible. $B$, support rods. $C$, control rod. $D$ iid. $E$, sustaining pin (4 $\mathrm{mm}$ carbon are rod). $F$, metal base. $G$, metal handle

The sample of metal thus obtained was allowed to freeze within the crucible and to cool to room temperature. Obviously, the mass of the metal did not change on cooling. The resulting ingot was weighed and the specific volume of the metal at the temperature of sampling was calculated by dividing the volume of the crucible at that temperature by the weight of the ingot. 
B. S. Journal of Research, RP399

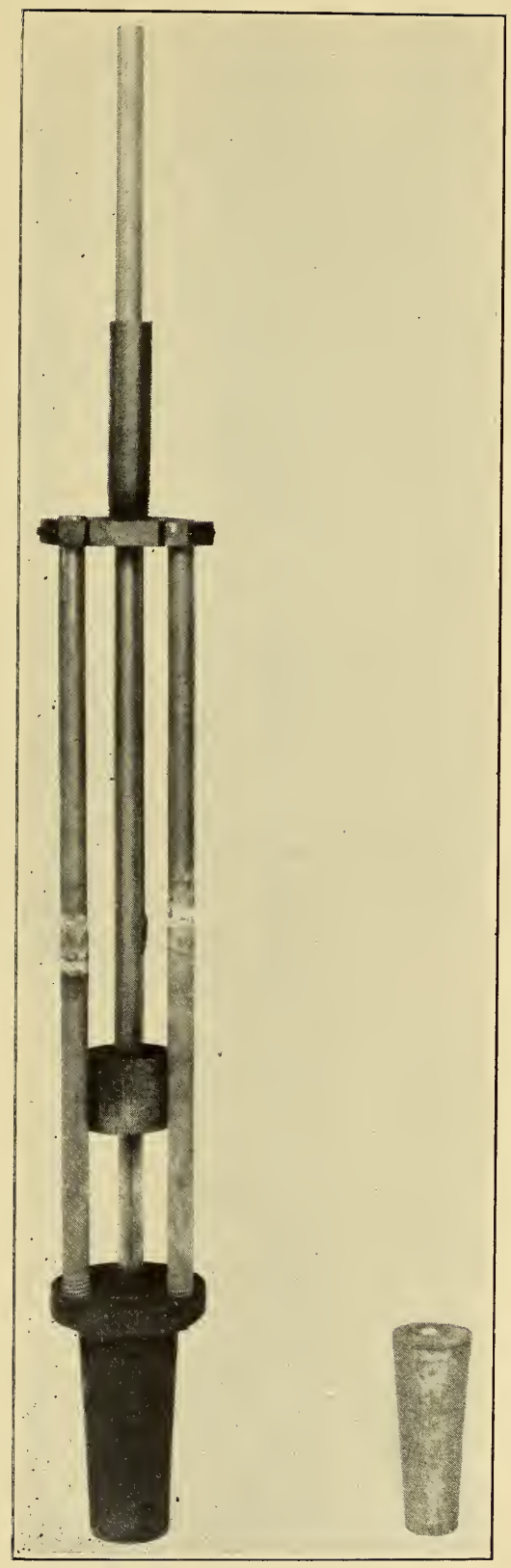

FIGURE 3.-Crucible immersion apparatus and ingot 
The volume of the crucible at room temperature was determined by weighing the mercury necessary to fill it when the lid was pressed down firmly and the volume at temperatures up to $600^{\circ} \mathrm{C}$. was calculated from the thermal expansion of graphite as given by Hidnert and Sweeney (33) up to $600^{\circ} \mathrm{C}$. The volumes at temperatures above $600^{\circ} \mathrm{C}$. were obtained by extrapolation. ${ }^{3}$

Graphite was found to be entirely suitable for the sampling of all the metals and alloys used with the exception of cast iron. A graphite crucible can not be used for obtaining samples of liquid iron because of the reaction between the iron and the graphite, which changes not only the dimensions of the crucible but also the composition of the iron.

It was found, however, that graphite can be protected from the action of molten cast iron by surfacing it with a refractory "wash." Zirconium oxide powder, to which had been added a small amount of colloidal clay for bond, mixed with water to a "consistency of cream" was found to be very satisfactory. No reaction of the graphite with the oxygen of the air can occur until the device has been removed from the melt. Oxygen may then penetrate through the surface layer and attack the underlying graphite. However, oxidation after removal of the apparatus from the bath does not affect the result.

No difficulty was experienced in removing the resulting ingot from a graphite crucible prepared in the above manner. It was possible to use the same immersion device for subsequent sampling, provided a fresh refractory coating was applied before each immersion. An individual assembly was required for each sample when a number of samples were taken during any particular determination.

The temperature of the molten metal was measured by means of a platinum-platinum rhodium thermocouple within a glazed porcelain protection tube placed inside a graphite tube 1 inch in diameter. The graphite tube was treated with the refractory coating described above when it was to be immersed in cast iron.

\section{(b) SOLID METAL}

In addition to determining the specific volume-temperature curve for the liquid metal, it is necessary to determine the same for the metal after solidification. Thermal expansion data for many pure metals are available in the literature, and can be used for determining: the specific volume-temperature relations for the solid metal. In the case of gray cast iron, however, thermal expansion data obtained by heating a gray-iron casting would not answer the purpose because it is well known that heating a gray-iron casting results in permanent growth. It was necessary, therefore, to obtain data on the linear contraction of the metal as it cooled from the melt.

The dimensional changes occurring during the cooling of cast iron are affected by the separation of graphite. On freezing and during cooling, the cementite undergoes a partial transformation to ferrite and graphite. Since the specific volume of graphite is approximately

\footnotetext{
${ }^{3}$ Since the graphite used in the present investigation corresponds to the material investigated by Hidnert and Sweeney in 1927 , their data were used for extrapolation instead of the values given by Day and Sosman in 1912 (J. Ind. and Chem. Eng., vol. 4, p. 490; 1912). Day and Sosman obtained lower values for the coeffcients of expansion on a graphite rod prepared from one-half inch diameter electrode which was formed from much smaller aggregate particles than the 14-inch electrodes used by Hidnert and Sweeney. The long extrapolation involved in calculating the crucible volumes at elevated temperatures introduces some uncertainty in the specific volumes of the liquid metal.
} 
three times that of cementite, this transformation results in an increase in volume. This increase varies with the amount of cementite decomposed and, therefore, is dependent on the composition of the metal, particularly the carbon, silicon, and manganese contents, and on the rate of cooling of the metal.

The dimensional changes resulting from the graphite separation are affected by everything that affects the cooling rate; that is, pouring temperature, thermal conductivity of the mold and metal, temperature of the mold, size of casting (total heat content), and thickness of cross section. No value for dimensional changes in the solid state should be given for a cast iron without specifying the composition with respect to total and combined carbon.

Data for calculating the changes in specific volume with change in temperature from the solidification temperature to room temperature were obtained by means of observations of the linear contraction of a cast bar as shown in Figure 4. The portion of the bar beyond the
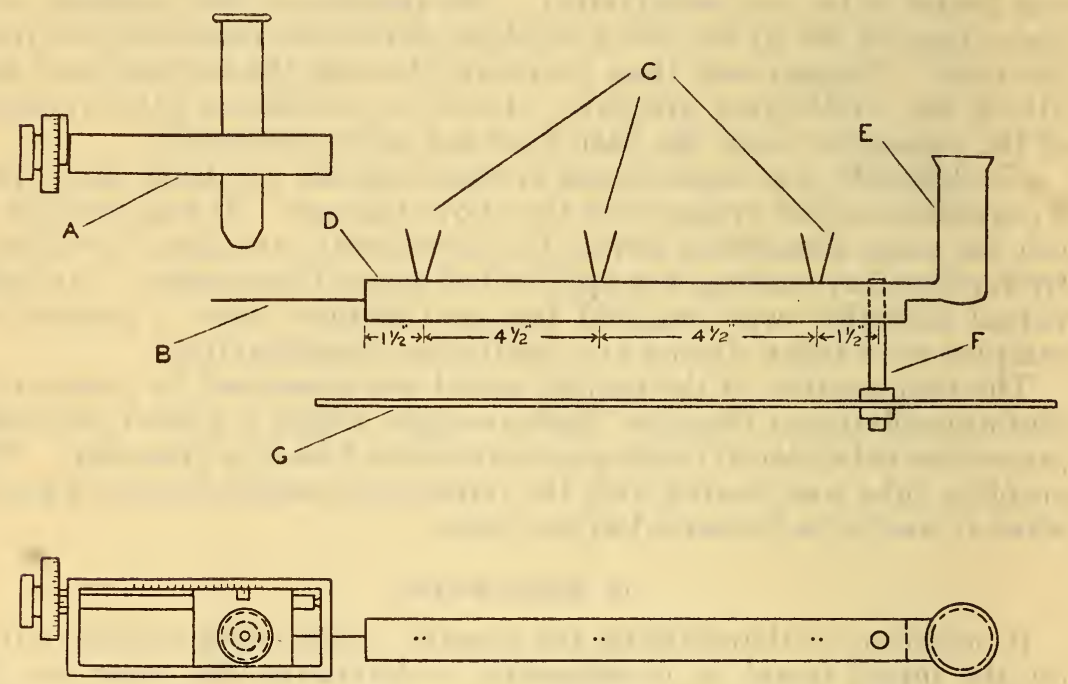

Figure 4.-Apparatus for measuring linear contraction of cast metals

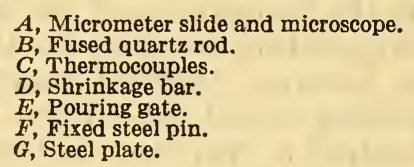

fixed pin can be of any convenient length and the cross section can be made to any convenient dimensions. In this investigation, three different sizes were used, namely, ${ }^{3 / 4}$ inch $(1.905 \mathrm{~cm})$ square, 1 inch $(2.54 \mathrm{~cm})$ square, and $1 \frac{1}{2}$ inch $(3.81 \mathrm{~cm})$ square, all 12 inches $(30.48$ $\mathrm{cm}$ ) long.

A fused quartz rod was used to indicate the linear movement of the cast bar on cooling. The rod was allowed to project into the mold cavity about one-eighth of an inch to insure that it would be firmly gripped by the metal on casting. The coefficient of thermal expansion of fused quartz is much less than that of iron, namely, $0.53 \times 10^{-6}$ 
for fused quartz (35) and $14.7 \times 10^{-6}$ for iron (36) (between room temperature and $600^{\circ}$ C.) The small movement of the cast bar as transmitted through the quartz rod was measured by means of a microscope mounted on a micrometer slide. The mold was made of green sand.

Turner (7), in measuring the total linear contraction of gray cast iron as it cooled from the end of the freezing range to room temperature, used a metal rod to join the movable end of his $T$ bar casting with his measuring device or extensometer. One end of the metal connecting rod was necessarily embedded in the end of the cast-metal bar. In this and subsequent work with this method, no corrections appear to have been made for the linear expansion of the metal connecting rod.

It was essential that the average temperature of the bar be obtained during the cooling interval. In order to secure this, three thermocouples were located in the 12 -inch cast bar at distances of $1 \frac{1}{2}, 6$, and $10 \frac{1}{2}$ inches, respectively, from the free end of the bar. It was assumed that an average of the three temperatures measured in this manner represented the average temperature of the bar. In practice, the three thermocouples, all of the same length and size, were joined in parallel, and the average temperature of all three was obtained by one reading of the instrument. Chromel-alumel thermocouples and a portable potentiometer indicator were used to indicate temperatures. The wires of the thermocouples were insulated from each other and from the molten metal by means of a sodium silicate silica-flour cement. The welded tip of each thermocouple extended into the mold cavity to one-half the thickness of the resulting bar.

The procedure followed in this determination was as follows: A shrinkage bar was cast by pouring metal from a ladle into a green sand mold. The temperature of the cast bar was read simultaneously with the observations on the movement of the quartz rod made by means of the microscope mounted on a micrometer slide. From these data the temperature contraction curve was constructed. The influence of cross-sectional area was studied by comparing data obtained from bars poured simultaneously of different cross-sectional dimensions.

\section{(c) SOLIDIFICATION RANGE}

For alloys which do not have a sharp freezing point, it was necessary to determine the liquidus point, the temperature at which incipient crystals form on cooling; and also the solidus point, the temperature at which incipient fusion begins on heating. The interval between these two temperatures is the solidification range. These temperatures were determined by thermal analysis methods.

Cast specimens 5 inches long and $1 \frac{1}{2}$ inches in diameter were used. A 3/8-inch hole, 4 inches deep, was drilled along the longitudinal axis of the cylinder into which was inserted a platinum-platinum rhodium thermocouple protected by means of a glazed porcelain tube. The specimen was mounted in a 4 -inch coil of a high-frequency induction furnace and the intervening space filled with zircon sand. The electromotive force developed by the thermocouple was measured by means of a potentiometer. The time in seconds required for each successive change of one-tenth millivolt was recorded and inverserate heating and cooling curves of the specimen were obtained. The $89194-32-4$ 
liquidus point was taken as that temperature at which the first break occurred in the cooling curve, and the temperature of the solidus point as the first break in the heating curve.

\section{RESULTS}

\section{SPECIFIC VOLUME-TEMPERATURE CURVES}

Specific volume-temperature curves were determined for a number of nonferrous metals and cast irons.

The specific volume of liquid aluminum at $770^{\circ} \mathrm{C}$. was calculated as follows from experimental data obtained with the crucible immersion apparatus:

Temperature of liquid aluminum at time of sampling

Weight of aluminum ingot....

Volume of graphite immersion crucible at $20^{\circ} \mathrm{C}$

Average cubical coefficient of expansion of graphite $\left(20^{\circ}\right.$ to $770^{\circ} \mathrm{C}$.)

Total change in temperature of graphite crucible heated to sampling

temperature $\left(770^{\circ}\right.$ to $20^{\circ}$ C.)

Volume change per milliliter $\left(750 \times 10.6 \times 10^{-6}\right) \ldots 080$

Volume increase for crucible $(67.64 \times 0.0080) \ldots$

Volume of crucible at $770^{\circ}$ C. $(67.64+0.54) \ldots$

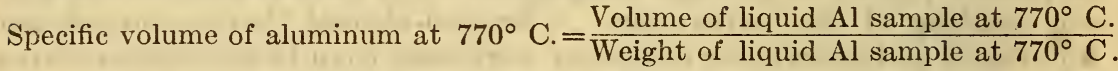
$=\frac{\text { Volume of graphite crucible at } 770^{\circ} \mathrm{C} .}{\text { Weight of Al ingot at room temperature }}=\frac{68.18}{160.99}=0.4235 \mathrm{ml} / \mathrm{g}$.

In a similar manner, the specific volume of liquid aluminum was determined at other sampling temperatures. By plotting these values against the corresponding temperatures, the upper portion of the curve in Figure 5 was obtained which represents the specific volume of liquid aluminum at various temperatures.

Change of length with temperature measurements were made on a 1-inch square bar of aluminum of 99.2 per cent purity during the period of cooling from its freezing point $\left(658^{\circ} \mathrm{C}\right.$.) to room temperature. As may be observed from the lower portion of the curve represented in Figure 5, the solid specific volume-temperature curve tends to flatten out just below the melting point. Possibly this was to be expected, since the cast bar may not have been sufficiently rigid at this high temperature to register the true contraction taking place. For the purpose of this investigation, this condition was overcome by extrapolating the main portion of the curve to the melting point.

The observed linear contraction of the bar, 12 inches long at the casting temperature, from the freezing point to room temperature was 0.213 inch (1.78 per cent) and as corrected for the extrapolated portion, 0.222 inch, or 1.85 per cent.

The cubical contraction of the metal is taken as three times the linear contraction. The value, 5.55 per cent $(3 \times 1.85$ per cent) represents the decrease in volume undergone by aluminum in cooling from the freezing point to room temperature $\left(20^{\circ}\right.$ C. $)$, and agrees closely with the linear contraction of aluminum of the same purity calculated, by extrapolation, from the thermal-expansion data given by Hidnert (37).

The specific volume $\left(\frac{1}{\text { density }}\right)$ of the metal was obtained on the cast 
bar after forging. The cross-sectional area was reduced 400 per cent by forging at $400^{\circ} \mathrm{C}$. The forged bar was annealed at $450^{\circ} \mathrm{C}$. for one hour. The specific volume of a sample cut from this bar was determined as $0.3683 \mathrm{ml} / \mathrm{g}$ at $20^{\circ} \mathrm{C}$. The corresponding specific volume of aluminum in the solid state at $658^{\circ} \mathrm{C}$. is $0.3903 \mathrm{ml} / \mathrm{g}$ as computed on the basis of the specific volume of the metal at $20^{\circ} \mathrm{C}$. and the contraction of 5.55 per cent occurring in cooling from $658^{\circ}$ to $20^{\circ} \mathrm{C}$.

By extrapolating that portion of the curve (fig. 5) representing the specific volume of liquid aluminum, to the freezing point $\left(658^{\circ} \mathrm{C}\right.$.)

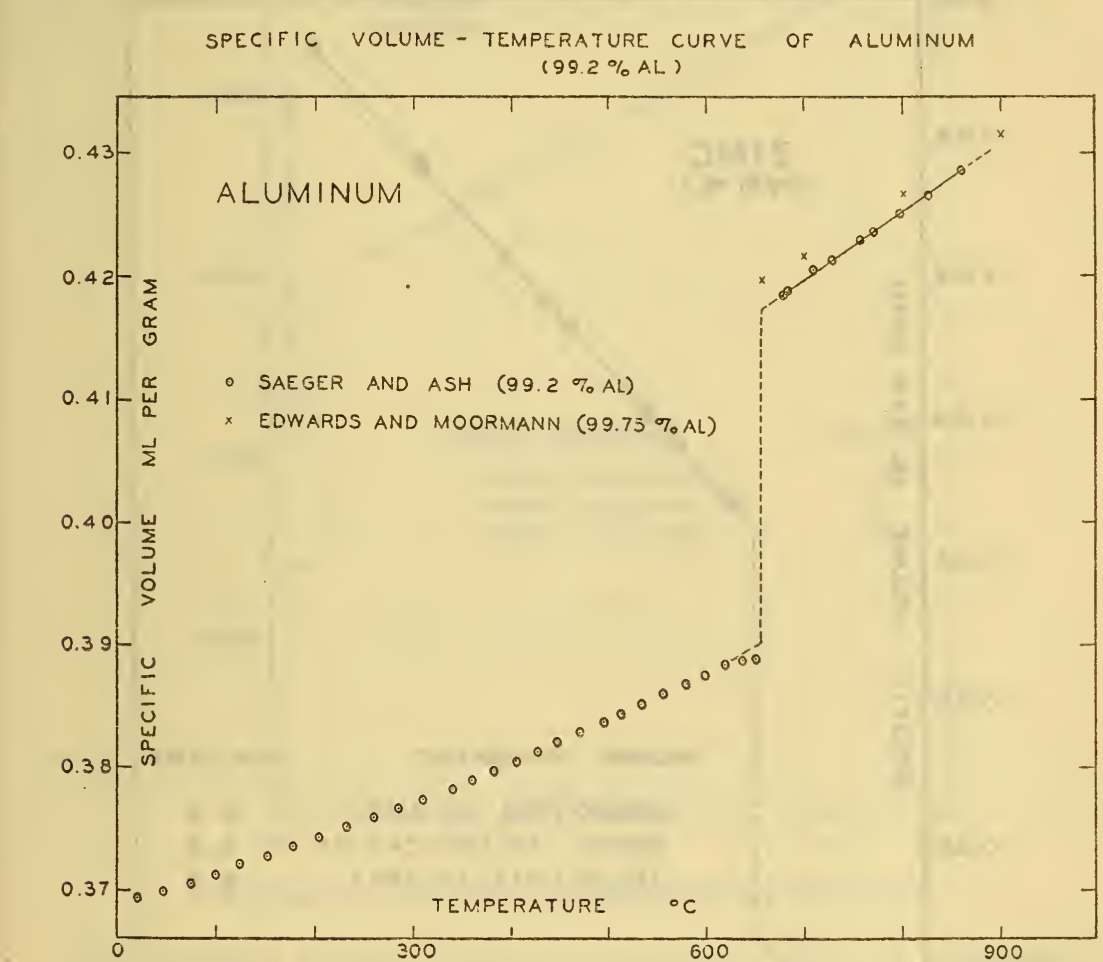

RP399

Figure 5.-Specific volume temperature curve of aluminum

Shrinkage during solidification: 6.5 per cent; solid shrinkage $\left(658^{\circ}\right.$ to $25^{\circ} \mathrm{C}$.) 5.5 per cent

the specific volume of liquid aluminum at the freezing point was found to be $0.4173 \mathrm{ml} / \mathrm{g}$. The difference between the specific volumes of the solid and liquid aluminum at the freezing point, the change in the specific volume due to solidification shrinkage, is equal to $0.4173-0.3903=0.0270 \mathrm{ml} / \mathrm{g}$. This is equivalent to 6.5 per cent, as based on the specific volume of the liquid at the freezing point.

The specific volume-temperature curve for the aluminum in the solid state may also be computed from the coefficient of linear thermal expansion. The average coefficient of linear expansion of aluminum of the purity used in this work was determined by Hidnert (36) as $28.7 \times 10^{-6}$ for the temperature range from $20^{\circ}$ to $600^{\circ} \mathrm{C}$. By extrapolating to $658^{\circ} \mathrm{C}$., the average coefficient of linear expansion for the 
temperature range $20^{\circ}$ to $658^{\circ} \mathrm{C}$. was found to be $29.0 \times 10^{-6}$. This latter coefficient, multiplied by the difference in temperature, times 100 , gave the per cent linear contraction of this aluminum in passing from the freezing point at $658^{\circ}$ to $20^{\circ} \mathrm{C}$. as 1.85 per cent. The value determined by observation of the linear contraction of the cast bar coincides with this value. The calculation of the specific volume of the solid at the melting point has been described previously.

Anderson (15) found his results for the linear contraction of aluminum and many of its alloys varied, as follows: Other conditions

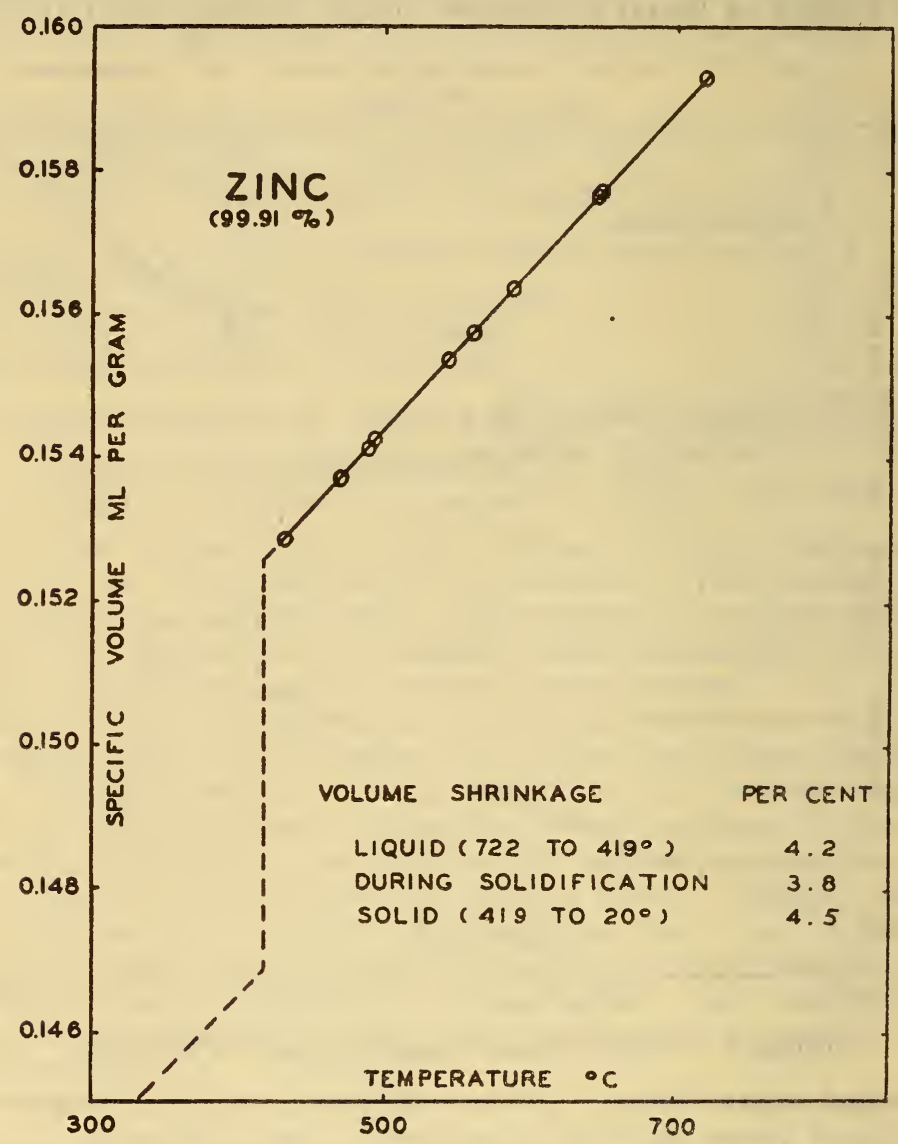

Figure 6.-Specific volume-temperature curve of zinc

being equal, he found that $(a)$ the smaller the cross section of a cast bar of given length, the less the contraction; $(b)$ the greater the length for a given cross section, the less the contraction; and $(c)$ the contraction was less in chill molds than in sand-cast molds.

Anderson's value for the total linear contraction of commercial aluminum was 1.68 per cent of the length of the solid bar at the freezing point, whereas the value calculated from the thermal expansion measurements of materials of the same purity is 1.85 per cent, as has been shown. 
Coleman (38), working with a 90 per cent gold, 10 per cent copper alloy obtained a net casting shrinkage of 1.25 per cent, whereas the contraction of the solid metal calculated from thermal expansion data was 1.62 per cent. Coleman suggested that the variation was probably due to stretching of the casting during cooling as a result of "hanging" to the mold wall or the feeding of metal during the cooling process.

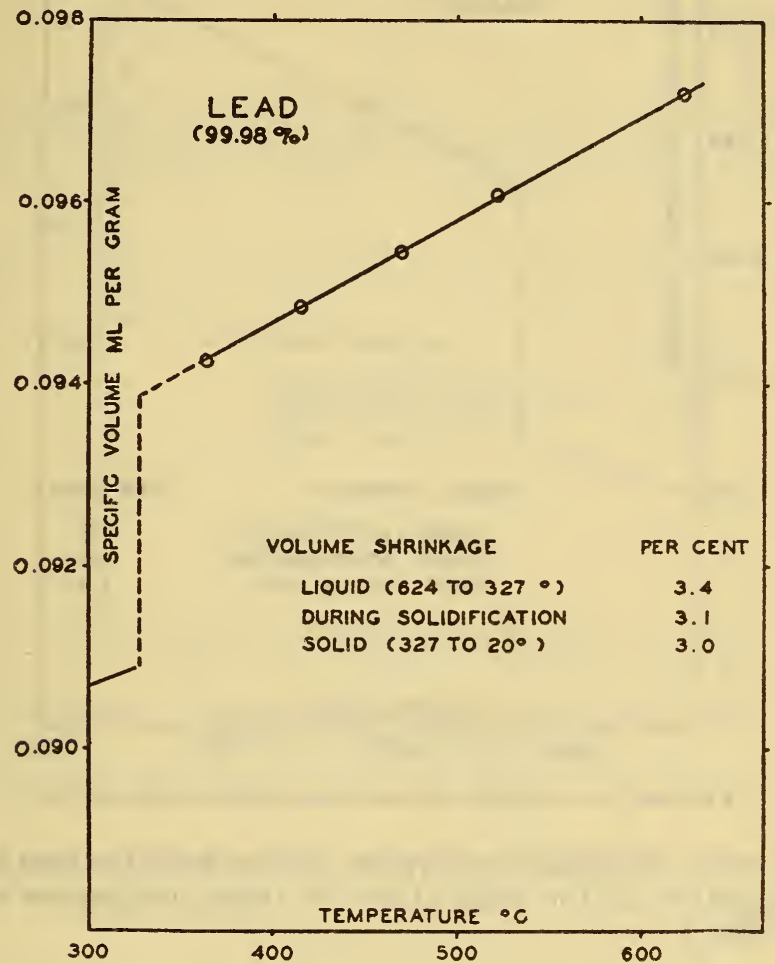

FIgURE 7.-Specific volume-temperature curve of lead

The complete specific volume-temperature curve of aluminum is shown in Figure 5. The values reported by Edwards and Moormann (25) are also plotted on this figure for comparison.

By similar procedure, specific volume-temperature curves were determined for zinc, lead, tin, a aluminum-copper alloy containing 8 per cent copper, and red brass of the nominal composition 85 per cent tin, 5 per cent each zinc, lead, and tin. With the exception of aluminum and red brass, the curves representing the specific volume of the solid state have been computed from the thermal expansion data given in the literature. The curves for these various metals are given in Figures 6 to 10, inclusive. 
The composition of the different metals and alloys used is given in Table 1.

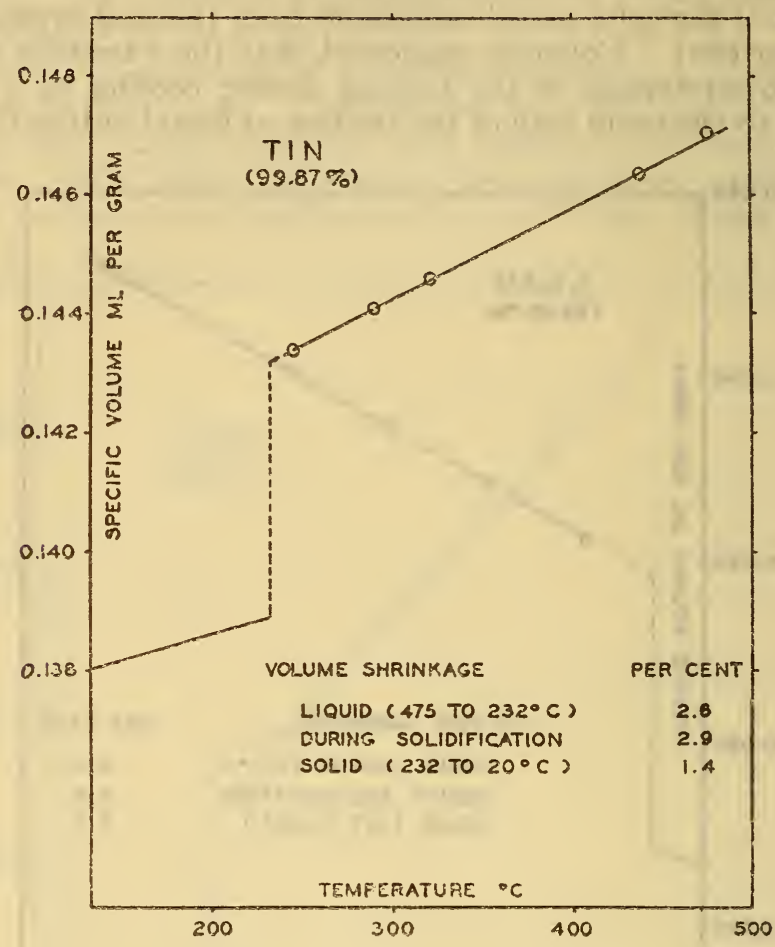

Figdre 8.-Specific volume-temperature curve of tin

Values for the shrinkage undergone during solidification and subsequent contraction in the solid state for these nonferrous metals are given in Table 2.

TABLE 1.-Chemical composition of nonferrous metals tested

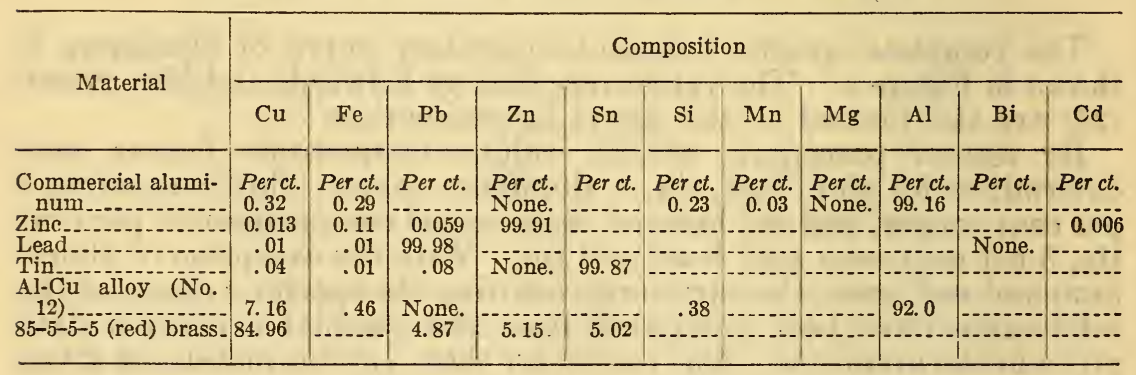




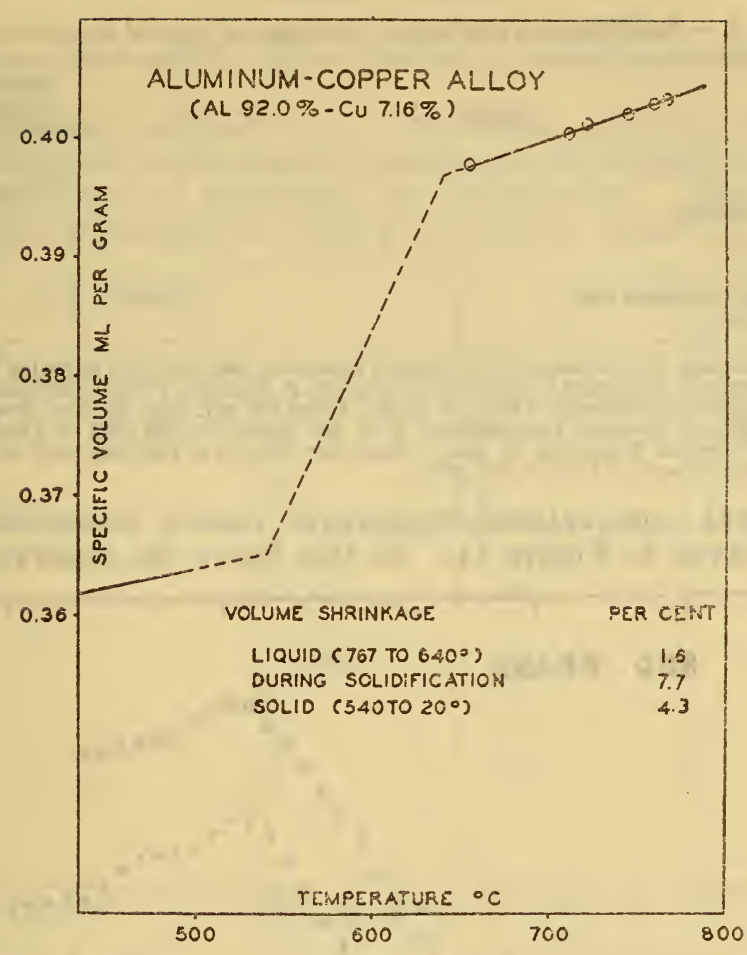

FigURE 9.-Specific volume-temperature curve of aluminum 8 per cent copper alloy

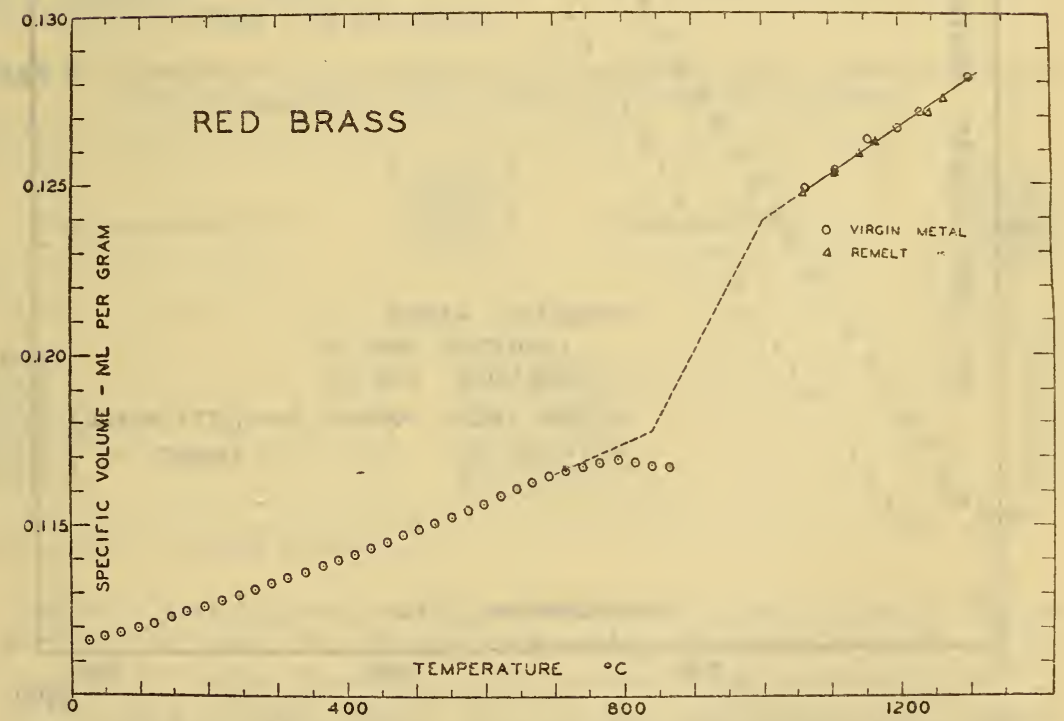

FigURE 10.-Specific volume-temperature curve of $85-5-5-5$ (red) brass Shrinkage during solidification, 5.0 per cent; solid shrinkage $\left(810^{\circ}\right.$ to $25^{\circ} \mathrm{C}$.), 4.5 per cent. 
TABLE 2.-Solidification and solid shrinkage of several nonferrous metals

\begin{tabular}{|c|c|c|}
\hline Metal & $\begin{array}{l}\text { Shrinkage } \\
\text { during } \\
\text { solidifica- } \\
\text { tion }\end{array}$ & $\begin{array}{l}\text { Shrinkage } \\
\text { from solid- } \\
\text { ification } \\
\text { to } 20^{\circ} \mathrm{C} .1\end{array}$ \\
\hline $\begin{array}{l}\text { Commercial aluminum } \\
\text { Zinc } \\
\text { Lead } \\
\text { Tin } \\
\text { Aluminum } 8 \text { per cent copper alloy } \\
\text { 85-5-5-5 (red) brass }\end{array}$ & $\begin{array}{r}\text { Per cent } \\
6.5 \\
4.5 \\
3.3 \\
2.9 \\
7.7 \\
5.0\end{array}$ & $\begin{array}{r}\text { Per cent } \\
5.5 \\
3.8 \\
2.9 \\
1.4 \\
4.3 \\
5.2\end{array}$ \\
\hline
\end{tabular}

1 The solid shrinkage was calculated from thermal expansion data from the following sources: (a) Com. mercial aluminum and aluminum 8 per cent copper alloy, P. Hidnert, Thermal Expansion of Aluminum and Various Important Aluminum Alloys, B. S. Sci. Paper No. 497; 1924; (b) Zinc, Freeman, Sillers, and Brandt. Pure Zinc at Elevated Temperatures, B. S. Sci. Paper No. 522; 1925; (c) Lead, P. Hidnert and W.T. Sweeney, Thermal Expansion of lead. Phys. Rev. vol. 35, p. 296; 1930; and (d) Tin, Cohen and Olei, Zeit. f. Phys. Chem., vol. 71 , p. $385 ; 1910$

The linear contraction-temperature curves determined for red brass are given in Figure 11. In this figure the observations made

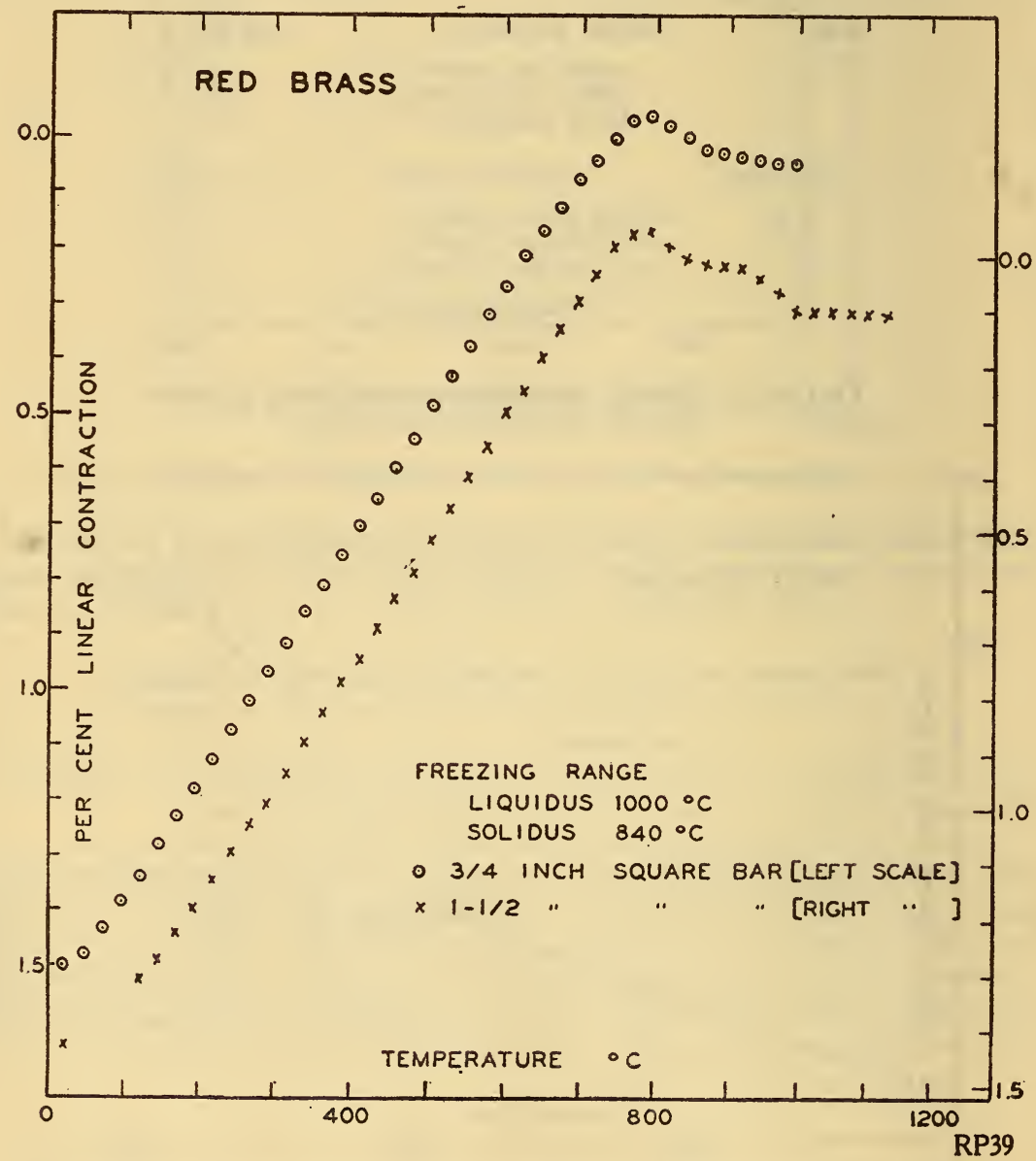

FigdRe 11.-Linear contraction-temperature curves of 85-5-5-5 (red) brass

above $800^{\circ} \mathrm{C}$. do not strictly represent the linear contraction of the metal because the method used is only adapted for determinations 
of shrinkage of the solid. They indicate marked expansion during freezing.

In Table 3 the coefficients of contraction calculated from data obtained on a $3 / 4$-inch square cast bar cooling in the sand are compared with the coefficients of expansion on the same bar. The shrinkage occurring during casting in cooling from $700^{\circ}$ to $20^{\circ} \mathrm{C}$. was 1.41
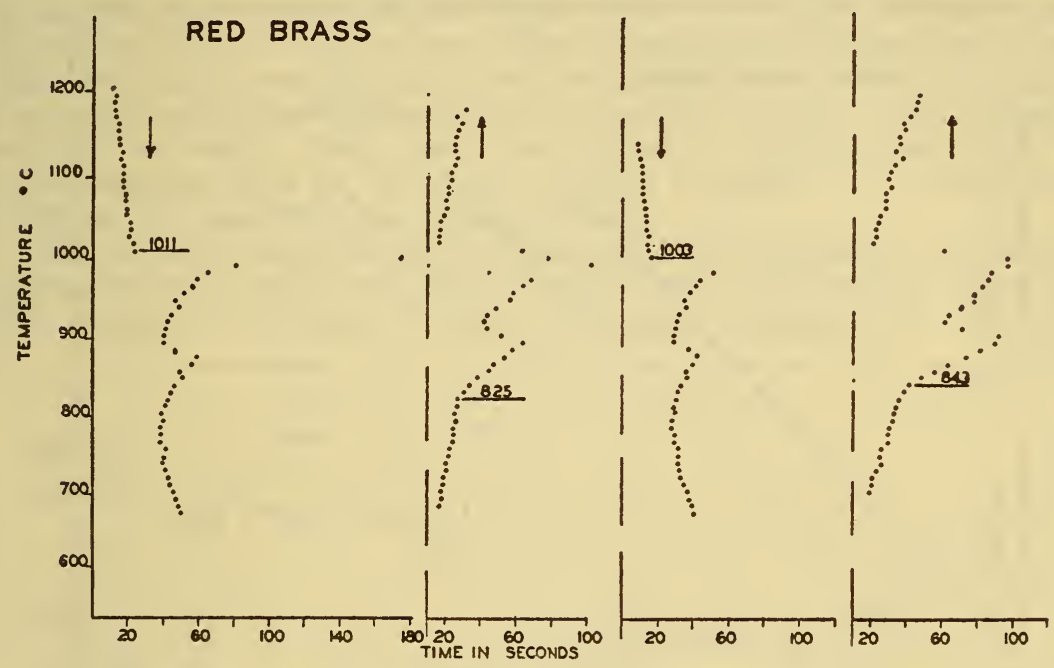

FIGURE 12.-Heating and cooling curves of $85-5-5-5$ (red) brass

per cent and the expansion on the first heating of the same bar from $20^{\circ}$ to $700^{\circ} \mathrm{C}$. was 1.40 per cent.

TABLE 3.-Comparison of the coefficients of contraction during casting and coefficients of expansion on first heating of $85-5-5-5$ (red) brass

\begin{tabular}{|c|c|c|c|}
\hline Temperature range $\left({ }^{\circ} \mathrm{C}.\right)$ & $\begin{array}{l}\text { A verage } \\
\text { coefficient } \\
\text { of linear } \\
\text { contrac- } \\
\text { tion per } \\
\text { o. }\end{array}$ & Temperature range ( $\left.{ }^{\circ} \mathrm{C}.\right)$ & $\begin{array}{l}\text { Average } \\
\text { coefficient } \\
\text { of linear } \\
\text { expansion } \\
\text { per }{ }^{\circ} \mathrm{C.} .\end{array}$ \\
\hline $\begin{array}{l}100 \text { to } 20 \\
200 \text { to } 20 \\
300 \text { to } 20 \\
400 \text { to } 20 \\
500 \text { to } 20 \\
600 \text { to } 20 \\
700 \text { to } 20\end{array}$ & \begin{tabular}{r|}
$\times 10^{-6}$ \\
16.5 \\
18.4 \\
19.1 \\
19.5 \\
19.8 \\
20.1 \\
20.8
\end{tabular} & $\begin{array}{l}20 \text { to } 100 \\
20 \text { to } 200 \\
20 \text { to } 300 \\
20 \text { to } 400 \\
20 \text { to } 500 \\
20 \text { to } 600\end{array}$ & $\begin{array}{r}\times 10^{-6} \\
17.8 \\
18.1 \\
18.5 \\
18.9 \\
19.3 \\
20.0 \\
20.6\end{array}$ \\
\hline
\end{tabular}

1 Determined by P. Hidnert, of this bureau.

A series of heating and cooling curves on red brass is given in Figure 12. The first break on cooling, indicating the liquidus point, occurs at about 1,005 while the solidus point occurs at approximately $840^{\circ} \mathrm{C}$.

As has been already stated, the data for constructing the specific volume-temperature curve of cast iron must necessarily be obtained for each individual iron studied from the behavior of the solid contraction bars. Figure 13 gives the linear contraction-temperature curves 
of two bars for one of the cast irons studied. ${ }^{4}$ As the specific volume (or density) of the different cast irons varies with each iron, according to the composition and rate of cooling, the density was determined for each bar. A slice, one-half inch thick, cut from the free end of the expansion bar was chosen as representative of the metal in that bar.

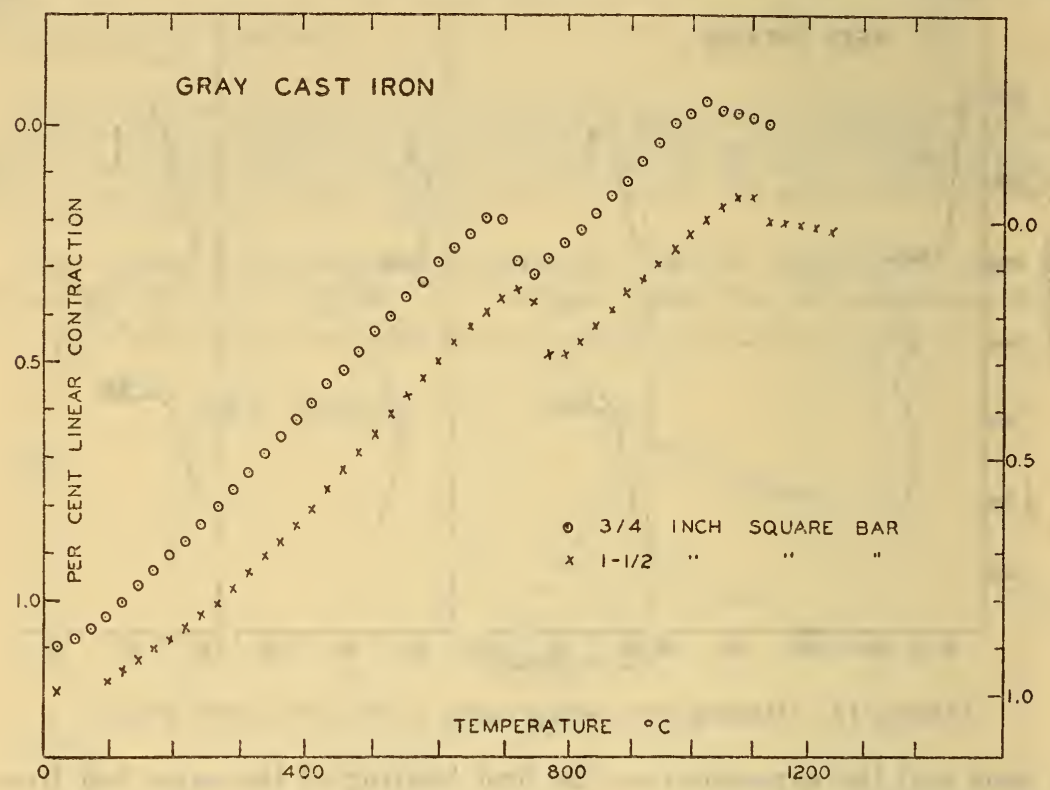

Figure 13.-Lincar contraction-temperature curves of gray cast iron Analysis: G. C. 2.90 ; C. C. 0.37 ; Si 2.87 ; Mn 0.52; P 0.59 ; S 0.03 per cent.

Typical results on the specific volume and contraction of a gray cast iron (G. C. 2.90 , C. C. $0.37, \mathrm{Si}, 2.87, \mathrm{Mn} 0.52$, and S 0.03 per cent) are given as follows:

Maximum heating temperature _...................... 1500

Temperature of liquidus point

Temperature of solidus point

Density at room temperature_...... $\left\{3 / 4\right.$-inch square $\mathrm{bar} \ldots \ldots \mathrm{g} / \mathrm{ml} \mathrm{r}_{-} \quad 7.095$

Specific volume at liquidus point $\left\{1 \frac{1}{2}\right.$-inch square bar-_._do-_- 7.092

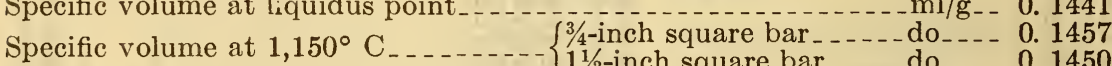

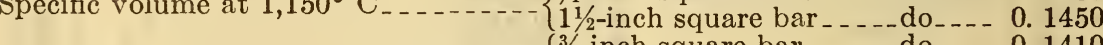

Specific volume at room temperature _ $\{3 / 4$-inch square bar _..._. do _._. 0.1410

Average

Average contraction of liquid per $100^{\circ} \mathrm{C}$. $\left(1,400^{\circ}-1,150^{\circ} \mathrm{C}\right.$.).-per cent.- 1. 1

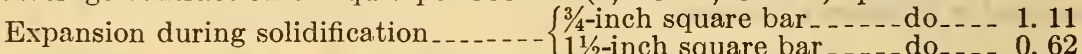

Linear contraction from $1,150^{\circ}$ to $25^{\circ}\{1 / 2$-inch square bar _..... do

C .

The specific volume-temperature curve for cast iron was obtained in the manner described above, with the exception that the density at room temperature is that of the metal as cast. A typical curve for gray cast iron is given in Figure 14. 


\section{DISCUSSION}

The calculated volume change during solidification is dependent upon the value of the specific volume at room temperature. The specific volume of a metal as ordinarily cast in molds may approach but will not coincide with the true specific volume of the metal. It is generally believed that the density of a cast metal is lower than its true density because of minute gaps in the crystalline structure produced by different orientations of the microcrystals and gas inclosures. The true specific volume or its reciprocal, the density, of a cast specimen can be obtained by mechanically working the specimen with subsequent annealing (cast iron an exception). Likewise, any error in the shrinkage data of the solid will also introduce a corresponding error in the solidification volume change.

Due to the many factors influencing the contraction in the solid state, the data obtained from a contraction bar are not absolute. The results on the same irons made under presumably the same

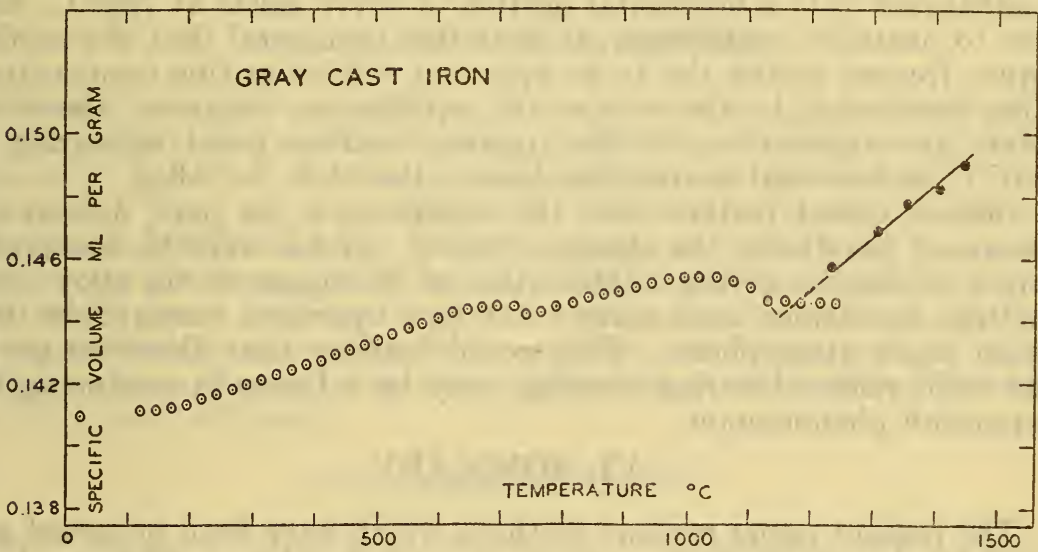

Figure 14.-Specific volume-temperature curve of gray cast iron

Analysis: G. C. 3.36 ; C. C. 0.41; Si 2.14; Mn 0.55; P 0.44; S 0.04 per cent

operating conditions vary. Thus, the contraction data presented for cast iron during solidification and for the solid are only relative. It is apparent that the error introduced by using the specific volume of the casting at room temperature, a value that is greater than the true specific volume, reduces the calculated shrinkage resulting from solidification.

The linear contraction-temperature curve of red brass (fig. 11) is somewhat similar in appearance to the curve of gray cast iron in that a marked expansion occurs during solidification. This was more pronounced in the larger bars. For red brass, the expansion begins at approximately $1,000^{\circ} \mathrm{C}$. and reaches a maximum at $800^{\circ} \mathrm{C}$.

Turner and Murray (8) reported an expansion of pure aluminum during freezing. In the discussion of this paper, Rosenhain pointed out that "once the metal was solid, no doubt the instrument would respond with some considerable degree of accuracy to the expansions or contractions of the metal; but before some sort of more or less rigid connection had been established between the extensometer bar and the fixed pin in the molding flask, he (Rosenhain) could not see what 
necessary connections existed between the movements of the extensometer and any volume change."

In a discussion of a paper by Ewen and Turner (9), Desch stated that he agreed that the volume would vary in proportion to the length after the bar was once solidified. He also suggested that any observed expansion during solidification may be due to crystal thrust.

Chamberlain (12) studied a series of copper-aluminum alloys with respect to their behavior during solidification by means of an apparatus similar to Turner's. He found a distinct relationship between the expansion curve during solidification and the crystallization interval curve. He states that the expansions are produced by forces of considerable magnitude.

Sauerwald (39) found a marked expansion for copper and coppertin alloys during solidification.

Boehm (40) studied the phenomenon of expansion during solidification of copper-tin alloys and the influence of gas atmosphere. He pointed out that in the copper-tin equilibrium diagram of Bauer and Vallenbruck (41) a horizontal portion of curve exists at $798^{\circ} \mathrm{C}$. and, due to unstable equilibrium, it is at this horizontal that the mother liquor freezes, giving rise to an apparent solidus at this temperature. This horizontal in the copper-tin equilibrium diagram, therefore, offers an explanation for the apparent solidus point appearing at $800^{\circ} \mathrm{C}$. in the solid contraction bars of the $85-5-5-5$ alloy.

Boehm stated further that the expansion is, in part, due to the release of gas during the change of state. In his work he observed a larger expansion during solidification of 90 copper-10 tin alloy when melting operations were carried out in a hydrogen atmosphere than in an argon atmosphere. This would indicate that dissolved gas in the melt, released during freezing, may be a factor in producing the expansion phenomenon.

\section{SUMMARY}

The present paper reviews methods which have been proposed and used for determining the various types of shrinkage undergone by a cooling metal; defines the three types of shrinkage to be consideredshrinkage of liquid metal, shrinkage during solidification, and shrinkage of the solid metal; and considers in detail two experimental methods, namely, the sand-cast-cone method and the method depending on the determination of the specific volume-temperature relations of the metal.

Reliable shrinkage data were not obtained by use of the sand-castcone method, for the following reasons: $(a)$ The temperature of the metal at the instant the mold cavity is completely filled can not be determined, since there is no uniformity of temperature throughout the mass of metal in the mold cavity; $(b)$ a volume change takes place in a portion of the metal within the mold cavity (due to chilling of the metal along the sand surfaces) during the period of pouring the casting, and a certain amount of feeding of the casting has taken place before the mold cavity has filled with metal.

2. The second and more accurate experimental method used is that which depends upon the construction of the specific volume-temperature curve for the metal under consideration. The specific-volume temperature curve for liquid metal was constructed from data secured by filling a crucible of known volume with the liquid metál at a known 
temperature. Since the mass of the sample of liquid metal is the same as that of the sample at room temperature, the liquid specific volume can be readily calculated.

3. Data on the contraction of the solid metal were obtained by direct observations of the change in length with change in temperature of a sand-cast bar of metal. The difference between the specific volume of the solid metal and of the liquid metal at the melting point is the shrinkage resulting during solidification. In the case of an alloy, shrinkage during solidification occurs over a range of temperature. The freezing range of alloys was determined by heating and cooling curves.

4. Typical experimental data and calculations are given, and shrinkage values for the metal in the liquid state, during solidification, and the solid state were determined for commercial aluminum, red brass $(85-5-5-5)$ and a cast iron. Shrinkage of the liquid metal and shrinkage during solidification have also been determined for an aluminum 8 per cent copper alloy, and for lead, zinc, and tin.

\section{ACKNOWLEDGMENTS}

The authors wish to express their appreciation to the American Foundrymen's Association for their cooperation in this investigation, especially to Dr. J. T. MacKenzie, chairman of the Committee on Research. They are also indebted to a number of individuals of the Bureau of Standards staff for their assistance, especially to Louis Jordan for his suggestions, advice, and constructive criticism; to Lemuel D. Jones for preparing molds and castings; to W. F. Roeser for his able assistance on the work on thermal analysis; to E. L. Peffer for his work on density of the various specimens; and to Peter Hidnert for his valued criticisms.

\section{BIBLIOGRAPHY}

1. W. P. Davey, A Theory of the Mechanism of Crystal Growth, Phys. Rev., vol. 29 , p. $206 ; 1927$.

2. Y. Matuyama, On the Density of Molten Metals and Alloys, Sci. Repts., Tohoku Imperial University, vol. 18, p. 19; 1929.

3. W. E. Goodrich, Volume Changes During the Solidification of Metals and Alloys of Low Melting Point, Trans., Faraday Soc., vol. 25, p. 531; 1929.

4. C. Benedicks, D. W. Berlin, and G. Phragmen, A Method for the Determination of the Specific Gravity of Liquid Iron and Other Metals of High Melting Point, Iron and Steel Inst., Carnegie Scholarship Memoirs, vol. 13, p. 129; 1924.

5. C. Benedicks, N. Ericsson and G. Ericson, Bestimmung des Spezifischen Volumes von Eisen, Nickel und Eisenlegierungen im geschmolzenen Zustand, Archiv für das Eisenhüttenwesen, vol. 3, p. 473; 1930.

6. W. J. Keep, Cooling Curves and Tests for Cast Iron, J. Iron and Steel Inst., vol. 48, p. $227 ; 1895$.

7. T. Turner, Volume and Temperature Changes During the Cooling of Cast Iron, J. Iron and Steel Inst., vol. 69, p. 48; 1906.

8. T. Turner and M. T. Murray. The Copper-Zinc Alloys-A Study of Volume Changes, J. Inst. Metals, vol. 2, p. 98; 1909.

9. D. Ewen and T. Turner, Shrinkage of Antimony-Lead Alloys and of Aluminum Zinc Alloys During and After Solidification, J. Inst. Metals, vol. 4, p. 128; 1910.

10. A. Hague and T. Turner, The Influence of Silicon on Pure Cast Iron, J. Iron and Steel Inst., vol. 82, p. 72; 1910.

11. J. L. Houghton and T. Turner, Volume Changes in Alloys of Copper with Tin, J. Inst. of Metals, vol. 6, p. 192; 1911. 
12. J. H. Chamberlain, A Study of Volume Changes in Alloys. J. Inst. Metals, vol. 10 , p. $193 ; 1913$.

13. F. Wüst, Shrinkage of Metals and Alloys, Metallurgie, vol. 6, p. 769; 1909.

14. F. Johnson and W. G. Jones, New Forms of Apparatus for Determining the Linear Shrinkage and for Bottom-Pouring of Cast Metals and Alloys, Accompanied by Data on the Shrinkage and Hardness of Cast Copper-Zinc Alloys. J. Inst. of Metals, vol. 28, p. 299; 1922.

15. R. J. Anderson, Linear Contraction of a Series of Brasses and Bronzes, Trans. Am. Fdymen's Assn., vol. 31, p. 371; 1923; and Linear Contraction and Shrinkage of a Series of Light Aluminum Alloys, Trans. Am. Fdymen's Assn., vol. 31 , p. $392 ; 1923$.

16. K. Bornemann and F. Sauerwald, Density Measurements of Metals and Alloys. Zeit. f. Metallkunde, vol. 14, p. 145; 1922.

17. H. Endo, On the Measurement of Change of Volume During Solidification, Sci. Repts., Tohoku Imp. Univ., vol. 13, p. 193; 1924.

18. H. Endo, On the Volume Change in Alloys During Solidification, Sci. Repts., Tohoku Imp. Univ., vol. 13 , p. 219; 1924.

19. K. Honda and H. Endo, On the Volume Change in Cast Iron During Solidification, Sci. Repts., Tohoku Imp. Univ., vol.16, p. 19; 1927.

20. Russell, Allen, and Goodrich, British Nonferrous Metals Research Association Report, Ser. 85; 1925.

21. Y. Matuyama, On the Volume Changes in Certain Type Metals During Solidification, Sci. Repts., Tohoku Imp. Univ., vol. 17, p. 1; 1928.

22. Y. Matuyama, On the Volume Change of Manganese During Solidification, Sci. Repts., Tohoku Imp. Univ., vol. 18, p. 733; 1929.

23. K. Honda, T. Kase, and Y. Matuyama, On the Change of Volume of Cast Iron During Solidification, Sci. Repts., Tohoku Imp. Univ., vol. 18, p. 699; 1929.

24. C. H. Desch and B. S. Smith, Interim Report on the Density of Molten Steel. J. Iron and Steel Inst., vol. 119, p. 538; 1929.

25. J. D. Edwards and F. A. Mooremann, Density of Aluminum from $20^{\circ}$ to $1,000^{\circ}$ C., Chem. \& Met. Eng., vol. 24, p. 61; 1921.

26. J. D. Edwards, Mechanism of Solidification of a Copper-Aluminum Alloy, Chem. \& Met. Eng., vol. 24, p. 217; 1921.

27. J. D. Edwards and H. T. Gammon, Causes of Piping in Aluminum Ingots, Chem. \& Met. Eng., vol. 24, p. 338; 1921.

28. Thomas D. West, Molders' Text Book, John Wiley \& Sons, p. 6; 1909.

29. O. Smalley, Volume Changes of Cast Iron on Solidification, Inst. of Brit. Fdymen., vol. 16, p. 405; 1922-23.

30. J. Longden, Some Considerations on Liquid Shrinkage in Gray Cast Iron, Inst. of Brit. Fdymen., vol. 18, p. 573; 1924-25.

31. H. A. Schwartz, Shrinkage in White Cast Iron, Trans. Am. Fdymen's Assn., vol. 37 , p. $205 ; 1929$.

32. C. M. Saeger and E. J. Ash, Methods for Determining the Volume Changes Undergone by Metals and Alloys during Casting, Amer. Foundrymen's Association, vol. 38, p. $107 ; 1931$.

33. P. Hidnert and W. T. Sweeney, B. S. Tech. Paper No. 335; 1920.

34. N. L. Bowen, J. W. Greig, and E. G. Zies, Mullite, a Silicate of Alumina, J. Wash. Acad. Sci., vol. 14, p. 206; 1927.

35. W. Souder and P. Hidnert, B. S. Sci. Paper No. 524; 1925.

36. W. Souder and P. Hidnert, B. S. Sci. Paper No. 433; 1921.

37. P. Hidnert, Thermal Expansion of Aluminum and Various Important Aluminum Alloys. B. S. Sci. Paper No. 497; 1924.

38. R. L. Coleman, Physical Properties of Dental Materials (Gold Alloys and Accessory Materials), B. S. Jour. Research, vol. 1, (RP 32); December, 1928.

39. F. Sauerwald, Einiges über die Schwindung der Metalle Zeit. f. Metallkunde, vol. 21 , p. $293 ; 1929$.

40. F. Boehm, Ueber die Schwindung von Legierungen, Dissertation, Technischen Hochschule zu Breslau; 1930.

41. Mitt. a. d. Mat.-Prüf.-Amt., Berlin; 1922.

Washington, October 22, 1931. 